\title{
Cell Culture Growth Monitoring using Disposable Electrochemical Enzymatic Sensors
}

\author{
Pablo Fanjul Bolado ${ }^{1}$, Marta M.P.S. Neves ${ }^{1}$ María Begoña González García ${ }^{1}$, David Hernández \\ Santos ${ }^{1}$ \\ ${ }^{1}$ DropSens, S.L. Edificio CEEl, Parque Tecnológico de Asturias, 33428, Llanera, Asturias, Spain \\ Corresponding author: pfanjul@dropsens.com
}

\begin{abstract}
Determination of cell growth and viability is crucial for bioprocesses monitoring. Traditionally, the control of the cell culture growth is performed by cell counting, which can be a time-consuming procedure that requires an expert user. Thus, in order to take the cell culture control to the next level, electrochemical enzymatic sensors for the in-situ measurement of substrates and metabolites of interest in cell cultures were developed.

Two of the most commonly monitored parameters are glucose, as the major carbon and energy source, and lactate, as a metabolic product. Therefore, two amperometric enzymatic sensors specific towards this key analytes were developed. Glucose and lactate sensors were based on screen-printed miniaturized technology which allowed collecting samples from the media in order of microliters, without disturbing the cell culture. The proposed glucose and lactate sensors were able to distinguish differences in glucose and lactate levels in cell media $24 \mathrm{~h}$ after the cells have been seeded. Due to the quantitative establishment of the uptake of glucose and production of lactate it was possible to effectively control the growth process stages. Aspects such as the limits of detection, reproducibility and repeatability were studied and the figures of merit were obtained. The developed sensors revealed to be robust, highly stable, user-friendly and time-saving, demonstrating the possibility of being used as a cell culture monitoring trustful tool.
\end{abstract}

Key words: cell culture; enzymatic sensors; screen-printed electrodes, electrochemical devices, portable instruments,

\section{Introduction}

Cell culture is widely used in industrial manufacture of recombinant therapeutic proteins, pharmaceutical research, diagnostics or regenerative medicine. In order to ensure good process performance and consistent product quality, process parameters should be monitored and used in real-time for process control. Some of the parameters that are usually monitored are $\mathrm{pH}$, temperature, dissolved oxygen, viable cell density and metabolites like glucose and lactate, among others To develop and optimize a batch process, the feed strategy (media composition, amount, and timing) is typically adjusted, based on cell growth, nutrient consumption (glucose, glutamine) and product accumulation (lactate among others) to keep a high cell viability and cell specific productivity, and prolong culture duration. Cell culture growth are generally taken under control by expensive and long laboratory testing performed by direct sampling to evaluate the quality $[1,2]$. Therefore, electrochemical biosensors, especially enzymatic sensors (ES), appear as an interesting alternative to those conventional methods. Due to their excellent features, such as robustness, simplicity, low-cost, fastresponse time and capability of miniaturization, ES are known as reliable, low-cost, portable analytical devices for "in-situ" detection of different analytes Additionally, the development of small-sized screen-printed electrodes (SPEs), definitively contributed to positioning ES as excellent tools for decentralized assays with small sample consumption [3]. 
In this work two ES based on SPEs are presented as alternative tools to monitor in an easy way the glucose and lactate levels in culture media without the needs of the addition of any reagent. Different cell cultures, with different number of cells, were tested and the results revealed that the levels of both glucose and lactate detected with these enzymatic sensors are related with the number of cells presents in the culture.

\section{Experimental Section}

Glucose sensor device. Ferrocyanide/carbon screen printed electrodes were modified with a mixture of Glucose oxidase/ HRP enzymes. The methodology consisted on dropping on the electrochemical cell of the glucose sensor (DRP-GLU10) an aliquot of $50 \mathrm{uL}$ of culture media diluted in buffer solution of $0.1 \mathrm{M}$ Tris$\mathrm{HNO}_{3} \mathrm{pH}$ 7.2. Amperometric detection was carried out at fixed potential of $-0.1 \mathrm{~V}$ during 60 s.

Lactate sensor device: Ferrocyanide/carbon screen printed electrodes were modified with a mixture of Lactate oxidase/ HRP enzymes. The methodology consisted on dropping on the electrochemical cell of the lactate sensor (DRPLACT10) an aliquot of $50 \mathrm{uL}$ of culture media diluted in buffer solution of $0.1 \mathrm{M}$ Tris- $\mathrm{HNO}_{3} \mathrm{pH}$ 7.2. Amperometric detection was carried out at fixed potential of $-0.1 \mathrm{~V}$ during $60 \mathrm{~s}$.

The enzymatic reactions for each sensor are shown in figure 1 :

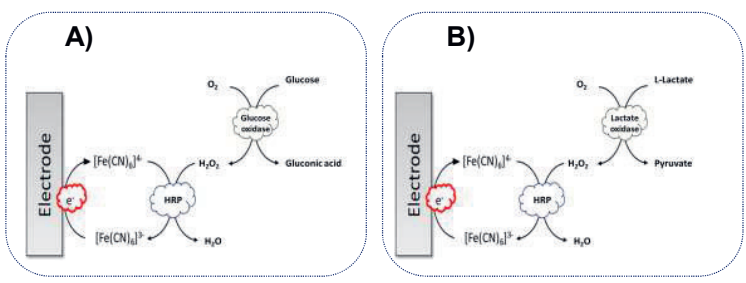

Fig. 1. Enzymatic reactions in A) glucose sensor and B) lactate sensor

The culture media and cells used in this work were EPILIFE, with corneal epithelium cells seeded, and DMEM + F12 (2:1), with skin epithelium cells seeded. In the case of EPILIFE medium a dilution factor of 1:100 was done in $0.1 \mathrm{M}$ Tris- $\mathrm{HNO}_{3} \mathrm{pH} 7.2$ buffer solution whereas for DMEM + F12 medium the dilution factor was 1:200. The media were measured with each sensor at $0,24 \mathrm{~h}, 48$ and 72 hours after the cells seeded. Moreover, different cell populations were seeded in each medium.

\section{Results}

The enzymatic sensors showed calibration plots with good regression coefficients (0.998) for concentrations comprised between 0.02 and $0.6 \mathrm{mM}$ for glucose and 0.02 and $0.3 \mathrm{mM}$ for lactate, respectively. Moreover, glucose consumption and lactate production were detected after $24 \mathrm{~h}$ of cell growth for all cell media assayed.

Figure 2 shows the values of glucose and lactate concentrations obtained with both enzymatic sensors for two times ( 0 hours and 72 hours) in each culture media, and they were compared with those obtained with commercial optical kits, achieving a good correlation between both methods, which corroborated a good sensors performance.
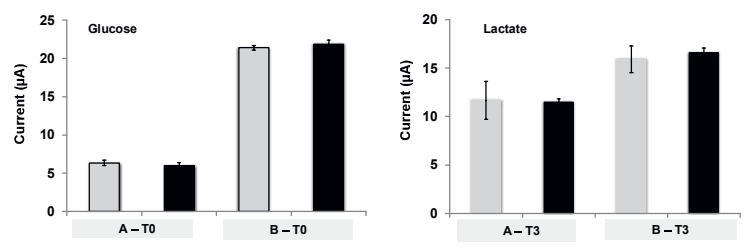

Fig. 2. Glucose and lactate concentrations measured with sensors (grey bars) and optical kits (black bars) for time 0 hours (TO) and 72 hours (T3) for EPILIFE (A) and DMEM + F12 (B) medium.

\section{Conclusions}

Quantitative measurement of glucose uptake and lactate production with developed sensors during cell growth allowed a specific and noninvasive evaluation of cell growth process and cell viability. The developed sensors revealed to be robust, highly stable, user-friendly and timesaving, demonstrating the possibility of being used as a cell culture monitoring trustful tool. Despite the good results more effords should be done with the aim of integrating these sensors in a flow system or into cell culture flasks, discs or plates in order to get an on-line monitoring system for achieving a continuous control of the cell growth.

\section{Acknowledgements}

This work was supported by the Project "BIOTEAR" (IDE/2016/0000216), cofinanced through IDEPA and ERDF fund.

\section{References}

[1] A. Zhang, V.L. Tang, B. Moore, V. Shen, Y.M. Huang, R. Kshirsagav, T. Ryll, Advanced Process Monitoring and Feedback Control to Enhance Cell Culture Process Production and Robustness, Biotechnol. Bioeng., 112 (2015) 2495-2504; doi: 10.1002/bit.25684

[2] V. Vojinovic, J.M.S. Cabral, L.P. Fonseca Realtime Bioprocess Monitoring: Part I: in situ Sensors, Sens. Actuators B Chem., 114 (2006) 1083-1091; doi: 10.1016/j.snb.2005.07.059

[3] F. Asrduini, D. Moscone, G. Palleschi, S. Piermarini, F. Ricci, G. Volpe, Electrochemical Biosensors Base don Nanomodified Screenprinted Electrodes: Recent Applications in Clinical Analysis, Trens in Anal. Chem., 79 (2016) 114126; doi: 10.1016/j.trac.2016.01.032. 